\title{
SGK1, the New Player in the Game of Resistance: Chemo-Radio Molecular Target and Strategy for Inhibition
}

\author{
Cristina Talarico ${ }^{\mathrm{a}}$ Vincenzo Dattilo ${ }^{\mathrm{a}}$ Lucia D'Antona $^{\mathrm{a}}$ Miranda Menniti ${ }^{\mathrm{a}}$ \\ Cataldo Bianco $^{b}$ Francesco Ortuso $^{a}$ Stefano Alcaro ${ }^{a}$ Silvia Schenone \\ Nicola Perrotti ${ }^{\mathrm{a}}$ Rosario Amato ${ }^{\mathrm{a}}$ \\ aDepartment of "Scienze della Salute", University "Magna Græcia" of Catanzaro, Viale Europa, \\ Catanzaro, bepartment of "Medicina Sperimentale e Clinica", University "Magna Græcia" of Catanzaro, \\ Viale Europa, Catanzaro, 'Department of Farmacia, University of Genova, Genova, Italy
}

\section{Key Words}

SGK1 • Chemo-resistance • Radio-resistance • RAN/RANBP1 • MDM2 • SGK1 inhibitors

\begin{abstract}
The serum- and glucocorticoid-regulated kinase (SGK) family consists of three members, SGK1, SGK2 and SGK3, all displaying serine/threonine kinase activity and sharing structural and functional similarities with the AKT family of kinases. SGK1 was originally described as a key enzyme in the hormonal regulation of several ion channels and pumps. Over time, growing and impressive evidence has been accumulated, linking SGK1 to the cell survival, de-differentiation, cell cycle control, regulation of caspases, response to chemical, mechanical and oxidative injury in cancer models as well as to the control of mitotic stability. Much evidence shows that SGK1 is over-expressed in a variety of epithelial tumors. More recently, many contributions to the published literature demonstrate that SGK1 can mediate chemoand radio-resistance during the treatment of various human tumors, both in vitro and in vivo. SGK1 appears therefore as a dirty player in the stress response to chemical and radioagents, responsible of a selective advantage that favors the uncontrolled tumor progression and the selection of the most aggressive clones. The purpose of this review is the analysis of the literature describing SGK1 as central node of the cell resistance, and a summary of the possible strategies in the pharmacological targeting of SGK1.

\section{Insight into SGK1}

The serum- and glucocorticoid-regulated kinase 1 (SGK1) is a serine/threonine kinase, member of the AGK Kinase family, that shares structural and functional similarities with C. Talarico and V. Dattilo contributed equally to this work and thus share the first authorship.

Rosario Amato and Nicola Perrotti Department of "Scienze della Salute", University "Magna Græcia" of Catanzaro, Viale 


\section{Cellular Physiology Cell Physiol Biochem 2016;39:1863-1876 \\ \begin{tabular}{ll|l} 
DOI: 10.1159/000447885 & $\begin{array}{l}\text { O 2016 The Author(s). Published by S. Karger AG, Basel } \\
\text { www.karger.com/cpb }\end{array}$ \\
\cline { 2 - 3 }
\end{tabular} \\ Talarico et al.: SGK1 in Chemo- and Radio-Resistance}

AKT (Protein Kinase B), PKC (Protein Kinase C) and S6K (Ribosomal S6 Kinase) [1-3]. SGK1 is regulated at different levels by insulin, cAMP [4-6], IGF-1 (Insulin like growth factor-I) [7], steroids [8], IL-2 (Interleukin-2) [9] and TGF $\beta$ (Transforming growth factor-beta) [10] and has been considered an essential convergence point for peptide and steroid hormone regulation of ENaC-mediated $\mathrm{Na}^{+}$transport [11]. Interestingly, a SGK1 polymorphic variant, carried by approximately $3-5 \%$ of Caucasians and approximately $10 \%$ of Africans, is associated with type 2 diabetes, obesity and increased blood pressure [12]. This peculiar role of SGK1 suggested a possible involvement in the pathogenesis of some of the components of the metabolic syndrome, like insulin resistance and hypertension $[13,14]$. Obesity and metabolic syndrome are, in turn, associated with an increased risk of cancer [15]. As a matter of fact, the association between obesity and/or metabolic syndrome and an elevated mortality from cancer has been confirmed by several studies in different populations, so that obesity is now recognized to be a relevant cancer risk factor worldwide. Unfortunately, the underlying molecular mechanisms of this association are still lacking [16, 17].

SGK1 regulates, beside ENaC (amiloride-sensitive sodium channel), other ion channels (e.g., KCNE1/KCNQ1), carriers (such as NCC, NHE3, SGLT1), Na(+)/K(+)-ATPase, enzymes (including glycogen-synthase-kinase-3) and transcription factors or regulators (including FOXO3a, $\beta$-catenin, NF-kappaB, SP1, p27) [18-20]. Ion channel physiology and pathophysiology of membrane polarization have an impact on cell proliferation by mechanisms that have been only recently elucidated in part [21, 22]. Taken together, all this information suggests that SGK1, originally described as a kinase responsible for regulating several cellular ion channels and pumps [23-25], can indeed have a role in oncology and immunology as well [26-28]. SGK1 function is tightly dependent on mTOR phosphorylation. Following the mTOR-dependent hydrophobic motif (H-motif) phosphorylation on serine 422 [29], the kinase evolves into an open conformation for phosphorylation and full activation by 3-phosphoinositide-dependent kinase-1 (PDK1) [30]. Increased SGK1 expression and/or activity has been found in several human tumors, including breast [31, 32], tongue [33], ovarian [34], prostate [35], multiple myeloma [36] and non-small cell lung cancer [37]. Currently, SGK1 expression is described as related to events of invasiveness and metastasization [38-42]. Conversely, SGK1 knock-out models have been shown to be strongly resistant to chemical carcinogenesis [43]. It has recently been demonstrated that SGK1 is essential and limiting in regulating cell survival, proliferation and differentiation via phosphorylation of Mouse Double Minutes 2 (MDM2), which governs p53 ubiquitylation and proteosomal degradation [44]. SGK1 also affects mitotic stability in colon carcinoma cells by regulating the expression of RANBP1 (Ran-specific binding protein 1), the pivotal regulator of GTPase RAN. SGK1 modulates RAN/RANBP1 abundance at the transcriptional level via SP1 activation and phosphorylation on Serine 59, thus affecting taxol sensitivity in these cells [45]. Taken together, all the evidence points to SGK1 as a key element in the development and/or progression of human cancer (Fig. 1).

\section{SGK1 and chemo-resistance}

One of the first observations that postulated a role of SGK1 in chemo-resistance came from the work of Amato et al. in 2007. He showed that the ectopic IL-2 receptor expression in renal carcinoma cells was able to activate SGK1 through PI3K. Activated SGK1 mediates hyper-proliferation and survival, but also induces resistance to doxorubicin through a FAS/ FASL (CD95-CD95L) dependent mechanism [9].

In the last few years, several works have focused on AKT as an important mediator in the chemo-resistance [46]. Indeed, a great number of clinical trials evaluating the therapeutic efficacy of AKT inhibitors for cancer-treatment have been designed and conducted or are ongoing worldwide [47]. However, resistance to these inhibitors has been observed, typically in tumors characterized by elevated expression of SGK1 [31]. Therefore, the interest is now shifting to SGK1, due to its structural and functional similarity with AKT. SGK1 has the 


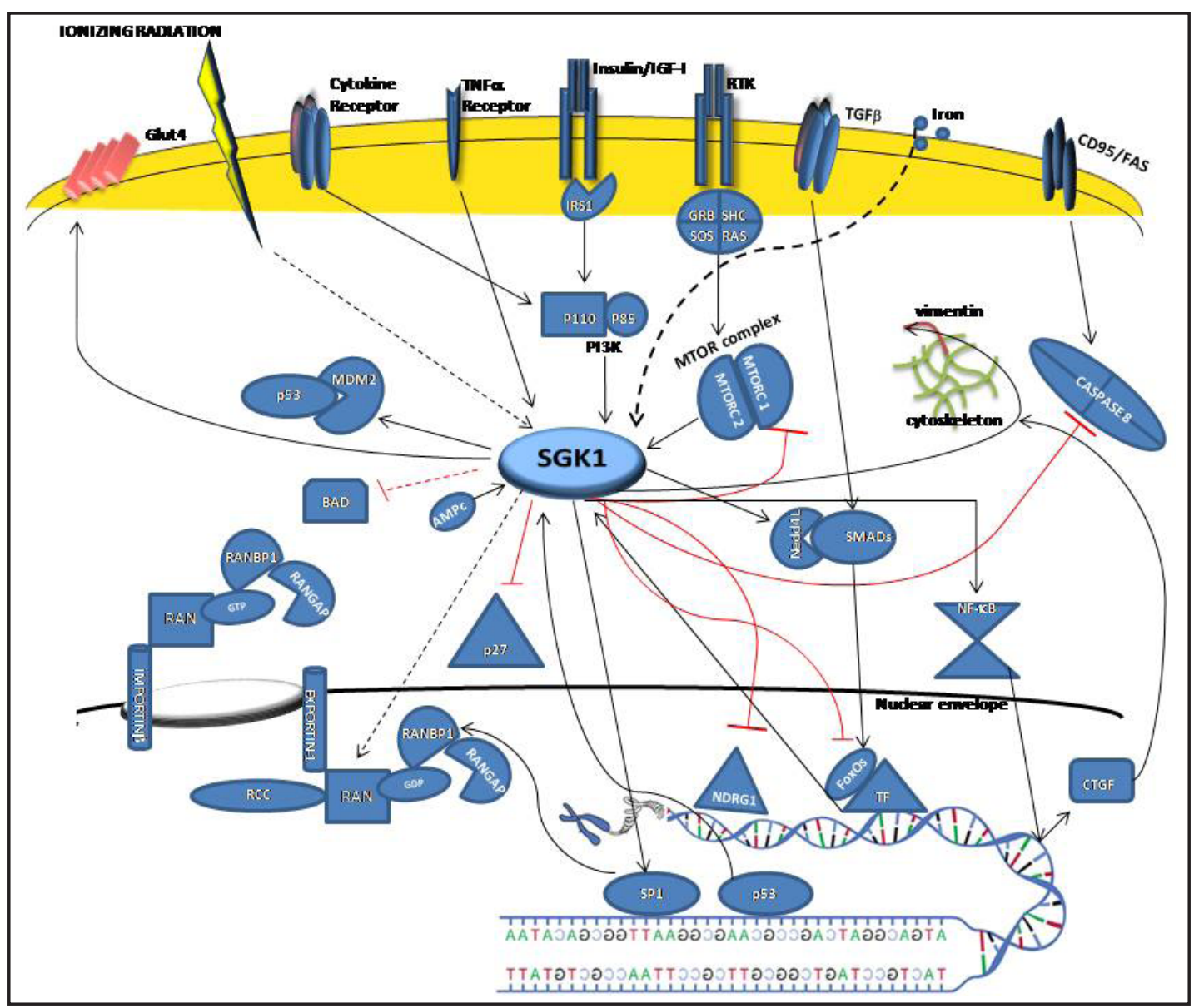

Fig. 1. Signaling pathway of SGK1 in neoplastic models. Black arrows: molecular activation with strong evidence in literature. Red arrows: molecular inactivation with strong evidence in literature. Black dashed line: molecular activation with slight evidence in literature. Strong: evidence supports a direct regulation/ interaction; Slight: evidence supports an indirect or mediated regulation/interaction.

potential to affect chemo-sensitivity of cancer cells through different mechanisms. One of these is dependent on the specific NDRG1 phosphorylation on three C-terminus residues (Thr328, Ser330 e Thr346) [48]. NDRG1 is considered an hallmark of carcinogenesis, by affecting cell proliferation, differentiation, migration, invasion, and stress response [49] as well as resistance to alkylating chemotherapy [50]. Multiple events, including stress signals, changes in the oxidative balance [51], nickel toxicity [52], DNA damage, elevated p53 expression [53] and hypoxia [54] stimulate the NDRG1 expression. The specificity of NDRG1 phosphorylation is still controversial, in fact NDRG1 appears to be phosphorylated by AKT in vitro, although less efficiently than SGK1 [48]. Sommer et al. showed that several breast cancer cells displaying high AKT and low SGK1 activity (BT-474, CAMA-1 and T47D) were sensitive to AKT inhibitors that also determined a decrease in NDRG1 phosphorylation. Conversely, in several breast cancer cell lines displaying high SGK1 activity (BT-549, JIMT-1, MDA-MB-436 e HCC-1937), NDRG1 phosphorylation is sensitive to SGK1 down regulation, but not to AKT inhibitors [31]. Since the expression of SGK1 is strongly induced by steroid hormones, including the glucocorticoids (e.g. dexamethasone) [55] which are routinely administrated in cancer patients, the concomitant use of glucocorticoids and AKT inhibitors may result in high SGK1 levels thus inducing chemo-resistance [31]. Briefly, SGK1 expression levels represent a predictive marker of response to AKT inhibitors in the treatment of breast cancer [31]. Moreover, the network SGK1/NDRG1 appears to be also implicated in the resistance

\section{KARGER}




\section{Cellular Physiology Cell Physiol Biochem 2016;39:1863-1876

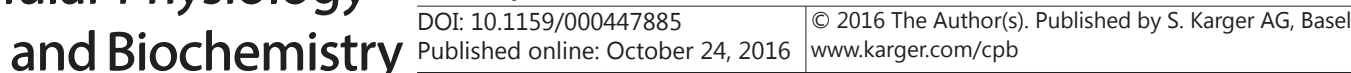 \\ Talarico et al.: SGK1 in Chemo- and Radio-Resistance}

to alkylating agents, such as temozolomide (TZM), commonly associated with radiotherapy in the treatment of malignant gliomas [56]. In malignant gliomas, NDRG1 is expressed at high levels and is considered predictive of poor response to alkylating-chemotherapy, via distinct molecular pathways involving hypoxia-inducible factor (HIF)-1alpha, p53 and the complex mTORC2/SGK1. In fact, the SGK1-dependent phosphorylation of NDRG1 on T346 is increased in TMZ-resistant cell lines. Accordingly, the pharmacological inhibition of SGK1 by EMD638683 overcomes the NDRG1- mediated resistance to TMZ. All the evidence points to NDRG1 as a predictive biomarker for TMZ response in advanced gliomas and suggests a possible therapeutic role of SGK1 inhibition [56]. This aspect has been also highlighted by Kim et al. and Skor et al. who defined the role of SGK1 in the resistance to paclitaxel in dexamethasone-pretreated MDA-MB-231 cells (GR+, triple negative breast cancer (TNBC) cells) $[57,58]$. In early-stage TNBC the high expression and activity of GR, positively correlates with chemotherapy resistance and increased recurrences. GR activation by either physiologic concentrations of glucocorticoids or dexamethasone treatment, mediates a potent antiapoptotic response, by stimulating SGK1 and MKP1/DUSP1 expression. This protective effect is observed when apoptosis is induced by growth factor deprivation or mediated by paclitaxel-based chemotherapy and is dependent on caspase-3 and PARP signaling both in vitro (MDA-MB-231 cells) and in vivo (TNBC xenograft model). Notably, in these conditions the addition of mifepristone, an antagonist of GR activity, blocks the GR-mediated survival of TBNC cells, and inhibits the expression of associated genes and apoptotic pathways [58]. Beside dexamethasone, oxidative stress also enhances the expression of SGK1, that in turn, inhibits SEK1 (MKK4/JNKK) by phosphorylation on Ser78, reduces SEK1 binding to JNK1 and counteracts the paclitaxel-induced apoptosis. In fact, the RNAi-mediated SGK1 depletion abolishes the dexamethasone-dependent inhibition of SEK1-JNK1 signaling and increases the paclitaxel-related cell death in MDA-MB-231 breast cancer cells[57]. Interestingly Ser78 in SEK1 is also a phosphorylation target of AKT through an oxidative stress/dexamethasoneindependent mechanism [59]. All these pieces of evidence together with the observation of high SGK1 expression in several breast cancers [60,61], suggest that the SGK1 inhibition and/ or GR antagonism can improve the efficiency of breast cancer treatment [57], particularly for patients with chemotherapy-resistant TNBC [58]. Another putative mechanism for the SGK1dependent paclitaxel resistance was described by Amato et al. in colon cancer cells. In this work it has been demonstrated that SGK1 affects taxol-induced mitotic arrest in RKO cells via modulation of RANBP1 expression [45]. RANBP1 is a major effector of the GTPase RAN: it cooperates with RANGAP1 (RAN GTPase-activating protein) in regulating GTP hydrolysis on RAN, thus promoting RAN-dependent signals in all downstream-regulated processes, such as nuclear import and export during interphase or mitotic spindle organization and nuclear reformation after mitosis [62-64]. RANBP1 expression is regulated by the transcription factor SP1, that is activated by SGK1-dependent phosphorylation on Ser59. As a result, SGK1 over-expression enhances RANBP1 transcript levels, whereas its silencing through RNA interference reduces RANBP1 abundance. Therefore, SGK1 silencing enhances taxolinduced apoptosis, recapitulating the effects of direct RANBP1 inactivation. Moreover, the ectopical RANBP1 expression counteracts the effects of SGK1 silencing in paclitaxel treated cells, proving that the effect of SGK1 on paclitaxel sensitivity is indeed mediated by RANBP1. An important implication of these findings is that SGK1 overexpressing tumors may be resistant to paclitaxel-dependent cell death due to their elevated RANBP1 expression [45]. Somewhat confirmatory data came from other groups. The modulation of miR-491-3p/ mTORC2/FOXO1 axis appears to be important in the development of chemo-resistance. miR491-3p was observed to be down-regulated in retinoblastoma cells under hypoxic condition [65] and in glioblastoma multiforme samples [66]. Zheng et al. have focused on the role of miR-491-3p in chemo-resistance of tongue cancer (TG). They found that the levels of miR491-3p were decreased in multidrug-resistant TC cells and that the induction of miR-491$3 p$ expression sensitized TC cells to chemotherapy. miR-491-3p directly targeted mTORC2 component Rictor and inhibited mTORC2 activity, which was increased in resistant TC cells with high p-AKT Ser473), p-SGK1(Ser422) and p-FOXO1(Thr24) levels [67]. 


\section{Cellular Physiology Cell Physiol Biochem 2016;39:1863-1876 \begin{tabular}{l|l|l} 
and Biochemistry Published online: October 24, 2016 & $\begin{array}{l}\text { (c) 2016 The Author(s). Published by S. Karger AG, Basel } \\
\text { www.karger.com/cpb }\end{array}$ \\
\hline
\end{tabular} \\ Talarico et al.: SGK1 in Chemo- and Radio-Resistance}

\section{SGK1 and radio-resistance}

In 2012 Feng et al. published on PNAS an impressive work that correlated the in vivo expression of SGK1 to the MDM2-dependent p53 degradation. SGK1 expression was up regulated in mice by means of chronic restraint stress that induced the activation of the hypothalamic-pituitary-adrenal axis. Activated SGK1 enhanced MDM2 mediated p53 degradation and greatly promoted ionizing radiation (IR)-induced tumorigenesis in p53(+/-) mice and, furthermore, promoted the growth of human xenograft tumors [68]. These data confirmed the first original demonstration that SGK1 was a key negative regulator of p53 through MDM2 activation [44]. Towhid et al. [69] demonstrated in a colon carcinoma (CaCo2) cell line that pharmacological inhibition of SGK1 by EMD638683 $(50 \mu \mathrm{M})$ synergized with low doses of radiation (3GY), causing mitochondrial depolarization and late apoptosis (necro-apoptosis), with relative increase of caspase-3. Liu et al. [70] demonstrated that the treatment of MCF7 breast cancer cell lines with TAC (Testosterone albumin conjugates), triggers androgen receptor independent non genomic signaling mediated by the membrane androgen receptor and induces a calcium-dependent actin remodeling that sensitizes the cells to apoptosis. The concomitant use of a SGK1 specific inhibitor (EMD638683) potentiates the effects of TAC and synergizes with radiotherapy. The authors conclude that mAR activation in combination with SGK1 inhibition and radiation may provide a powerful novel anti-tumorigenic strategy in the combat against breast cancer [64]. The role of SGK1 in the development of radio-resistance of human tumors was later extensively analyzed as a key theme by Talarico et al. [71, 72]. The effects of radiation therapy in cellular models of liver tumors in the presence of either SGK1 inhibition or SGK1 over-expression are described in a special section of this review [71]. Also in glioblastoma cells, the treatment with inhibitors of SGK1 was able to potentiate the effects of radiotherapy in a dose-dependent manner. In these cells radiotherapy exerts its anti-cancer effects through induction of ROS based oxidative-stress. Since SGK1 protects cells from oxidative stress mediated apoptosis, concomitant treatment with radiotherapy and the SGK1 inhibitor SI113 was indeed expected to circumvent the recovery from oxidative damage after irradiation. Similarly, radiotherapy in glioblastoma cells also induced cell death as a consequence of cytoplasmic-reticulum stress. Again, SGK1 allows recovery from such stress and SGK1 inhibition enhances the cytotoxic effects of radiotherapy mediated by cytoplasmic reticulum stress. These observations explain why the SI113-dependent SGK1 inhibition is able to exert a consistent additive effect with radiotherapy [72].

\section{The SGK1 kinase inhibitors: the new side of the force}

Under non pathological conditions, the expression of SGK1 results to be low in several tissues and apparently not required for basic functions. In fact, SGK1 knock-out mice show a very mild phenotype, only characterized by the inability to control sodium homeostasis when subjected to low sodium diet [24]. On the other hand, SGK1 is rapidly up-regulated under specific stress and pathological conditions [18]. In light of the emerging evidence highlighting a role for SGK1 in mediating several neoplastic features and properties, a real race to the definition of specific and selective inhibitors of SGK1 has arisen. The first inhibitor of SGK1 that was reported in the literature with potential therapeutic significance is a heterocyclic indazole derivate, later defined GSK650394 by Sherk et al. [73]. Originally described as being able to block the cell growth of androgen-dependent prostatic cell lines [73], GSK650394 has more recently shown some in vivo ability to synergize with cisplatin in the treatment of head/neck cancer and in the depletion of the CD44+ initiating-cancer cells [74]. However, the toxicity data of this molecule are not clearly and organically reported in the literature. Moreover, GSK650394 is equally active towards both SGK1 and SGK2. Besides, this inhibitor is only around 30-fold more selective for SGK1 than for IGF1R, Rho-associated protein kinase (ROCK), Janus kinase isoforms (JAK1, JAK3), protein kinase B isoforms (AKT1, 


\section{Cellular Physiology Cell Physiol Biochem 2016;39:1863-1876 \begin{tabular}{ll|l} 
DOI: 10.1159/000447885 & $\begin{array}{l}\text { O 2016 The Author(s). Published by S. Karger AG, Basel } \\
\text { www.kargercom/cpb }\end{array}$
\end{tabular} Talarico et al.: SGK1 in Chemo- and Radio-Resistance}

AKT2, AKT3), dual-specificity tyrosine phosphorylation-regulated kinase (DYRK1A) and PDK1, and less than 10 fold selective for SGK1 than for Aurora and c-Jun N-terminal kinase $[73,75]$. The second oldest SGK1 inhibitor reported in the literature is a benzohydrazide derivative, named EMD638683 by Ackermann et al. [76]. Originally described as an inhibitor of the SGK1-dependent metabolic effects, it was more recently evaluated in experimental models of colon cancer. The molecule has been shown to induce apoptosis and modulate radiations-dependent effects, at least at very low dose-rate (3Gy). Also, in vivo EMD638683 has been able to prevent the chemically-induced colon carcinogenesis, in accordance with the murine knock-out model for SGK1 [69]. Specificity at the dose of $1 \mu \mathrm{M}$ has been well tested over a broad panel of kinases. The comparison revealed that EMD638683 has an inhibitory effect also on cAMP-dependent protein kinase (PKA), mitogen- and stress-activated protein kinase 1 (MSK1), protein kinase C-related kinase 2 (PRK2), and the SGK isoforms SGK2 and SGK3 [76]. However in oncological papers, the molecule was tested at a dose of 50 $\mu \mathrm{M}$ [69], that appears to be well beyond the one used for specificity assay. It is therefore not impossible that other kinases are inhib-

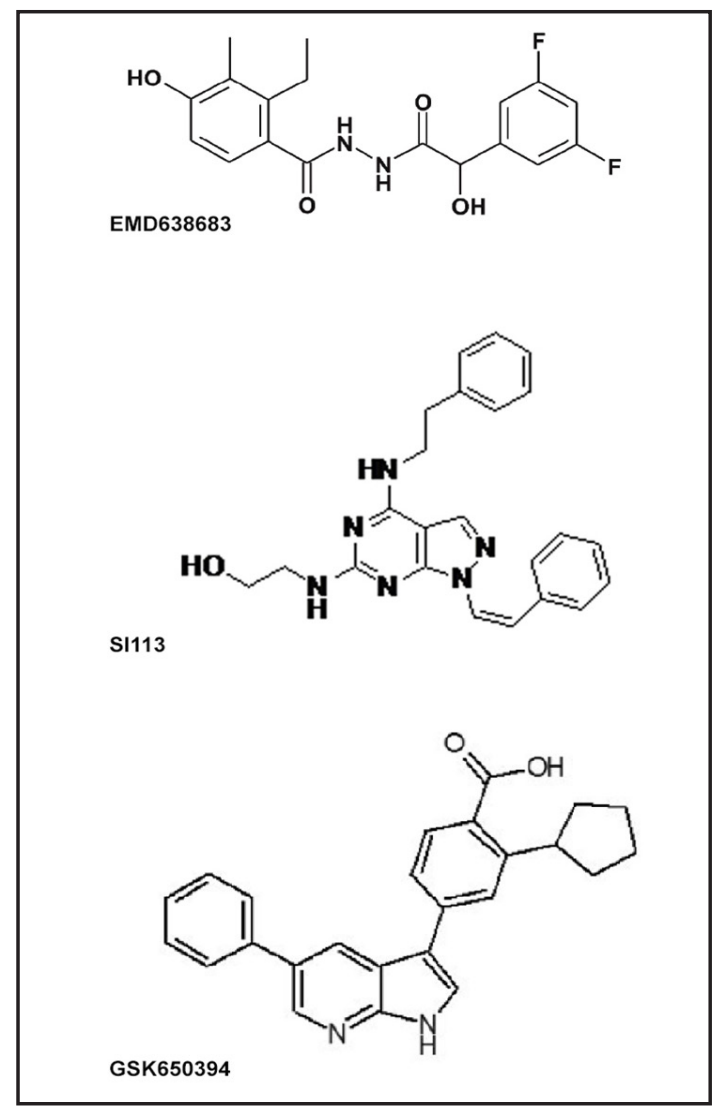

Fig. 2. Structural formula of EMD638683 (adapted from [76]), SI113 and GSK650394 (adapted from [73]). ited at this dose range. The structural formula of EMD638683 and GSK650394 are provided (Fig. 2, top and bottom panel). More recently, we screened a family of dual SRC/ABL small molecule inhibitors, characterized by a substituted pyrazolo[3,4- $d]$ pyrimidine scaffold, for their ability to inhibit SGK1 and AKT kinase activity, competing with ATP for its binding domain [77]. Among these molecules, SI113 (Fig. 2, middle panel) resulted particularly selective in inhibiting SGK1 kinase activity, while being much less effective on AKT1. A model of the in silico interaction between SI113 and the catalytic domain of SGK1 is provided in Fig. 3. A docking and chemical analysis revealed homologies among the target active sites: the ratio between average SGK1 and AKT1 values has shown differences in the range of 10\% for all measurements, except for the hydrophobic site. In fact, the SGK1 lipophilic area was $47 \%$ larger than that of AKT1. It is possible that the differential hydrophobic interaction may explain the preference of SI113 in SGK1 recognition and inhibition compared with AKT1. Moreover, a dose dependent curve of SI113-dependent SGK1 and AKT1 inhibition showed that the inhibition of the SGK1 activity occurred with an $\mathrm{IC}_{50}$ value of $600 \mathrm{nmol} / \mathrm{L}$ with a 100 fold selectivity compared to AKT1. In fact, AKT1 was inhibited with an $\mathrm{IC}_{50}$ value equal to 50 $\mu \mathrm{mol} / \mathrm{L}$ [77]. Similarly, the molecule was significantly less effective in the inhibition of other SI113-targeted substrates, toward which the molecules was originally developed e.g. ABL and SRC [78]. Additionally, in our hands, SI113 induced cell death, thus altering the growth rate in various malignant cell lines. Specifically, SI113 induced apoptosis in RKO colon carcinoma cells, both alone or synergizing with paclitaxel [78].

The three compounds were submitted to the ADME and molecular descriptor estimation using the Schrödinger Software Release 2015-4 (QikProp module). The detailed molecular descriptors and their ranges are listed in a novel comparative table (Table 1). 


\section{Cellular Physiology and Biochemistry

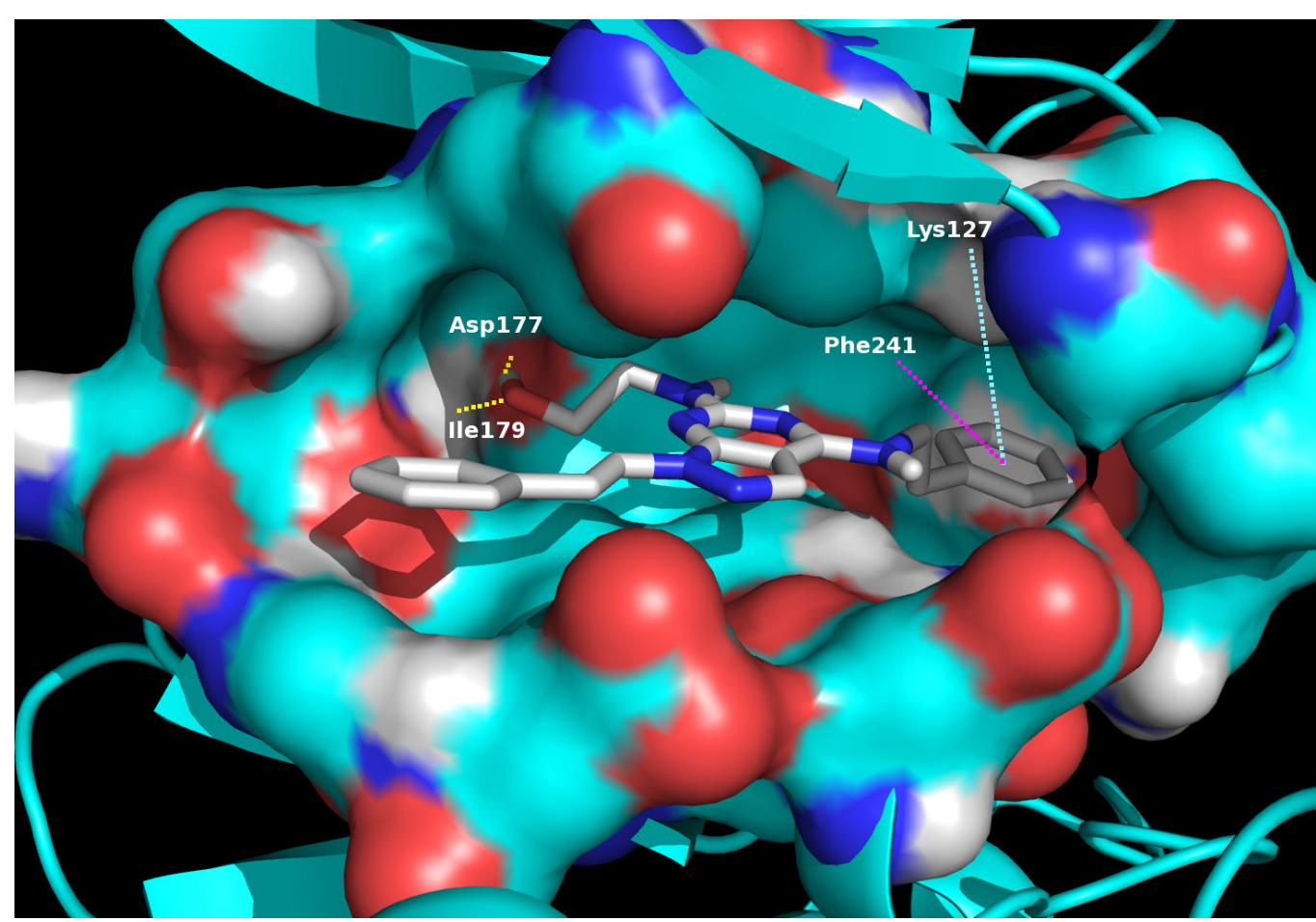

Fig. 3. SI113 recognition of SGK1.The inhibitor is depicted in polytube CPK colored, the enzyme active site residues are shown as surface, the rest of the enzymes is reportedas a cartoon. Yellow, purple or cyan dotted lines represent hydrogen bonds, cation- $\pi$, or t-shape $\pi-\pi$ interactions, respectively.

\section{Preclinical model in HCC: effective model for a SGK1 drug targeting in vivo: evidences of clinical synergy with radiation therapy}

Recently, genome-wide analysis of gene expression in human hepatocellular carcinoma cells (HCC) revealed that SGK1 and its cognate kinase AKT1 are similarly over-expressed when compared with normal human hepatocytes, thus indicating that both kinases might have roles in hepatocellular dysregulation [79-81]. In HCC, SGK1 is particularly relevant in highly malignant tumors characterized by epithelial-to-mesenchimal transition (EMT) that supports the underlying liver cirrhosis [80]. In a recently published work by Talarico et al. in Oncotarget [71], we learned relevant details in vivo and in vitro about specificity of the SI113-dependent SGK1 inhibition. In fact we first demonstrated that the SGK1 expression is mandatory for SI113 to decrease HCC cell viability and trigger apoptosis. In fact, SI113 is completely ineffective in SGK1 silenced cells by means of shRNA technology. Under these conditions SI113 not only lost its anti-proliferative and pro-apoptotic effects, but also showed a minimal anti apoptotic effect that possibly results from the interaction with other targets, in absence of SGK1. This, of course, provides an important indication for a possible clinical use of SI113 that must take into account the expression level of SGK1 as a therapeutic predictor. In the studied models of HCC, SGK1 pharmacological inhibition was also able to recapitulate the effect of SGK1 specific silencing, at least, in three pivotal pathways involved in the control of neoplastic transformation and development: mitotic stability, proliferation/ cell survival and response to chemo-radiogenic damage. Indeed SI113-dependent inhibition of SGK1 altered the expression and the function of RAN/RANBP1, MDM2/p53 and NDRG1. The ability of SI113 to regulate the expression and function of RANBP1/RAN plays an important role in HCC models. We previously demonstrated in models of colon carcinoma that the specific and stable SGK1 silencing led to a down regulation of RANBP1 and consequently altered the balance RANBP1/RAN. We also suggested that this effect involved SGK1 dependent phosphorylation and activation of SP1 transcription factor that governs 


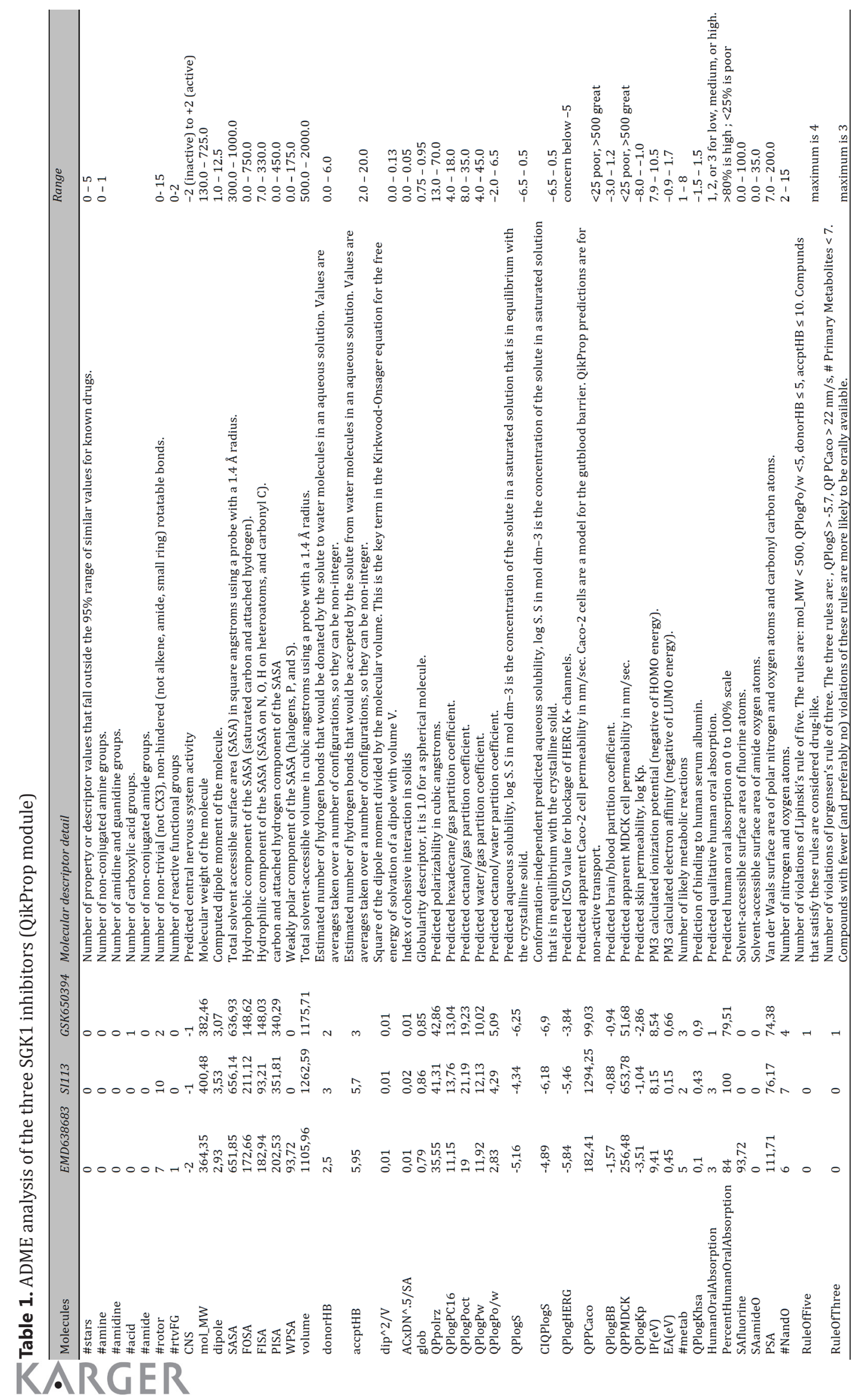




\section{Cellular Physiology Cell Physiol Biochem 2016;39:1863-1876 \begin{tabular}{ll|l} 
DOI: 10.1159/000447885 & $\begin{array}{l}\text { O 2016 The Author(s). Published by S. Karger AG, Basel } \\
\text { www.karger.com/cpb }\end{array}$ \\
\cline { 2 - 3 }
\end{tabular} \\ Talarico et al.: SGK1 in Chemo- and Radio-Resistance}

the expression of RANBP1 [45]. Now, also in liver models, we obtained similar results by SI113-dependent SGK1 inactivation. From a more functional point of view, however, the SI113-dependent SGK1 inhibition is expected to alter the capacity of RANBP1 to finetune the mitotic checkpoint and nuclear stability [82-86]. In fact, in our experimental conditions, treatment with SI113 determined a profound G2/M-phase perturbation [71]. This imbalance in the G2/M mitotic check point apparently makes the cells more sensitive to all those elements acting on this specific step (e.g. taxanes and X-ray damage). In the past, we demonstrated for the first time that SGK1 was able to regulate both in vivo and in vitro MDM2, through a specific phosphorylation on serine 166, thereby activating the ubiquitindependent degradation of p53 [44]. In Talarico et al. 2015 [71], we showed that the specific SI113-dependent inhibition of SGK1 caused a decreased phosphorylation of MDM2 that is expected to result in a reduced degradation of p53. This particular effect appears to be important for the regulation of proliferation and may have consequences in terms of cellular response to stress. MDM2 expression and activity is indeed considered as a marker of radiosensitivity [87]. We demonstrate that SGK1 expression levels affect the response to X-ray damage [71]. In fact, in cellular models of HCC, SGK1 over-expression causes an important increase in radio-resistance, whereas the specific SGK1 silencing causes an important increase in radio-sensitivity, when compared with the appropriate controls. Interestingly, the combined radiation/SI113 therapy induced an almost complete de-phosphorylation of MDM2 on serine 166 that may indeed explain the enhanced sensitivity to radiation. SII13 treatment also altered the phosphorylation and the abundance of NDRG1, a protein that has been proposed as a potential clinical target for HCC [88], thus suggesting another possible mechanism through which the SI113-dependent SGK1-targeting might be beneficial in HCC treatment. The data obtained by a proteomic approach after treatment with SI113 are also extremely interesting for the definition of new cellular pathways dependent on SGK1 in HCC. A number of new possible signaling pathways affected by the inhibition of SGK1 have been described, that may play a key role in the understanding the mechanisms of liver tumor formation and may also possibly disclose additional targets or factors of resistance to the treatment with SI113. We have, indeed, identified 85 proteins differentially modulated by SI113 dependent SGK1 inhibition. Among these, RAN and RANBP1 were confirmed to be down-regulated, as expected, together with important factors that are known to affect the cell cycle progression and the G2M transition: e.g. RHOA [89, 90], PAK2 [91], PHB [92]. SI113 treatment resulted in the up-regulation of the expression of onco-suppressive genes like ST-13 [56, 57] and MLC [39]. In this experimental work [71], however, the most important point was the analysis of the effectiveness of SI113 in vivo towards HCC xenografted in immunodeficient mice. The analysis of tumor volume and weight demonstrated that SI113 blocked tumor growth. Moreover, the evaluation by CT scanning corroborated the manual measurement on the tumor treated with either SI113 or vehicle alone, whereas histology demonstrated dramatic levels of necrosis in tumors from treated animals. No signs of toxicity or morbidity were observed by histological examination of the livers from treated mice, nor signs of generally adverse side effects or morbidity. In the light of this, we could conclude that SI113, alone or in synergy with radiotherapy, arrested tumor growth and induced cell death. These effects are specifically related to SGK1 inhibition, which basically turned off several pathways (e.g. RAN/RANBP1, MDM2/p53, NDRG1), that represent convergent molecular check-points of the oncogenic function of SGK1.

\section{Conclusion}

The increasing amount of data that underscores an essential and non-redundant role of SGK1 in the development and resistance of human tumors emphasizes that SGK1 represents an essential target in modern targeted therapy of tumors. The ability of SGK1 inhibitors to synergize with chemotherapy and radiation treatments, allowing a reduction of dose, and the evidence that SGK1 knock-out mice do not exhibit important pathological or toxic 


\section{Cellular Physiology Cell Physiol Biochem 2016;39:1863-1876

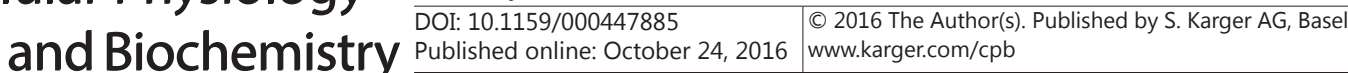 \\ Talarico et al.: SGK1 in Chemo- and Radio-Resistance}

effects, led to the definition of SGK1 as a stress-kinase hyper-activated in human tumors, whose inhibition may lead to a more favorable outcome with standard therapy.

\section{Acknowledgments}

This work was supported by FIRB BFR12NSCF_003 Young Investigator grant and AIRC project code 16971.

\section{Disclosure Statement}

The authors declare no commercial or financial conflicet of interest

\section{References}

1 Mora A, Komander D, Van Aalten DMF, Alessi DR: PDK1, the master regulator of AGC kinase signal transduction. Semin Cell Dev Biol 2004;15:161-170.

2 Frödin M, Antal TL, Dümmler BA, Jensen CJ, Deak M, Gammeltoft S, Biondi RM.: A phosphoserine/ threonine-binding pocket in AGC kinases and PDK1 mediates activation by hydrophobic motif phosphorylation. EMBO J 2002;21:5396-5407.

3 Bruhn MA, Pearson RB, Hannan RD, Sheppard KE: Second AKT: the rise of SGK in cancer signalling. Growth Factors 2010;28:394-408.

4 Perrotti N, He RA, Phillips SA, Haft CR, Taylor SI: Activation of serum- and glucocorticoid-induced protein kinase (Sgk) by cyclic AMP and insulin. J Biol Chem 2001;276:9406-9412.

5 Menniti M, Iuliano R, Amato R, Boito R, Corea M, Le Pera I, Gulletta E, Fuiano G, Perrotti N: Serum and glucocorticoid-regulated kinase Sgk1 inhibits insulin-dependent activation of phosphomannomutase 2 in transfected COS-7 cells. Am J Physiol Cell Physiol 2005;288:C148-155.

6 Boito R, Menniti M, Amato R, Palmieri C, Marinaro C, Iuliano R, Tripodi G, Cusi D, Fuiano G, Perrotti N: RFX1, a putative alpha Adducin interacting protein in a human kidney library. FEBS Lett 2005;579:6439-6443.

7 Boini KM, Bhandaru M, Mack A, Lang F: Steroid hormone release as well as renal water and electrolyte excretion of mice expressing PKB/SGK-resistant GSK3. Pflugers Arch 2008;456:1207-1216.

8 Chen SY, Bhargava A, Mastroberardino L, Meijer OC, Wang J, Buse P, Firestone GL, Verrey F, Pearce D: Epithelial sodium channel regulated by aldosterone-induced protein sgk. Proc Natl Acad Sci USA 1999;96:2514-2519.

9 Amato R, Menniti M, Agosti V, Boito R, Costa N, Bond HM, Barbieri V, Tagliaferri P, Venuta S, Perrotti N: IL-2 signals through Sgk1 and inhibits proliferation and apoptosis in kidney cancer cells. J Mol Med (Berl) 2007;85:707-721.

10 Lang F, Voelkl J: Therapeutic potential of serum and glucocorticoid inducible kinase inhibition. Expert Opin Investig Drugs 2013;22:701-714.

11 Faletti CJ, Perrotti N, Taylor SI, Blazer-Yost BL: sgk: an essential convergence point for peptide and steroid hormone regulation of ENaC-mediated Na+ transport. Am J Physiol Cell Physiol 2002;282:C494-500.

12 Schwab M, Lupescu A, Mota M, Mota E, Frey A, Simon P, Mertens PR, Floege J, Luft F, Asante-Poku S, Schaeffeler E, Lang F: Association of SGK1 gene polymorphisms with type 2 diabetes. Cell Physiol Biochem 2008;21:151-160.

13 Grundy SM, Brewer HB, Cleeman JI, Smith SC, Lenfant C: Definition of Metabolic Syndrome: Report of the National Heart, Lung, and Blood Institute/American Heart Association Conference on Scientific Issues Related to Definition. Circulation 2004;109:433-438.

14 Lang F, Stournaras C: Serum and glucocorticoid inducible kinase, metabolic syndrome, inflammation, and tumor growth. Hormones (Athens) 2016;12:160-171.

15 Feakins RM: Obesity and metabolic syndrome: pathological effects on the gastrointestinal tract. Histopathology 2016;68:630-640. 


\section{Cellular Physiology Cell Physiol Biochem 2016;39:1863-1876 \begin{tabular}{l|l|l|l|l}
\hline DOI: 10.1159/000447885 & $\begin{array}{l}\text { () 2016 The Author(s). Published by S. Karger AG, Basel } \\
\text { www.karger.com/cpb }\end{array}$
\end{tabular} \\ Talarico et al.: SGK1 in Chemo- and Radio-Resistance}

16 Mazzarella L: Why does obesity promote cancer? Epidemiology, biology, and open questions. Ecancermedicalscience 2015;9:554.

17 Bhaskaran K, Douglas I, Forbes H, dos-Santos-Silva I, Leon DA, Smeeth L: Body-mass index and risk of 22 specific cancers: a population-based cohort study of 5·24 million UK adults. Lancet 2014;384:755-765.

18 Lang F, Görlach A: Heterocyclic indazole derivatives as SGK1 inhibitors, WO2008138448. Expert Opin Ther Pat 2010;20:129-135.

19 Schmid E, Xuan NT, Zahir N, Russo A, Yang W, Kuhl D, Faggio C, Shumilina E, Lang F: Serum- and glucocorticoid-inducible kinase 1 sensitive NF- $\kappa B$ signaling in dendritic cells. Cell Physiol Biochem 2014;34:943-954.

20 Voelkl J, Castor T, Musculus K, Viereck R, Mia S, Feger M, Alesutan I, Lang F: SGK1-Sensitive Regulation of Cyclin-Dependent Kinase Inhibitor 1B (p27) in Cardiomyocyte Hypertrophy. Cell Physiol Biochem 2015;37:603-614.

21 Zhou Y, Wong CO, Cho K, van der Hoeven D, Liang H, Thakur DP, Luo J, Babic M, Zinsmaier KE, Zhu MX, Hu H, Venkatachalam K, Hancock JF: SIGNAL TRANSDUCTION. Membrane potential modulates plasma membrane phospholipid dynamics and K-Ras signaling. Science 2015;349:873-876.

22 Zhang W, Qian C yun, Li SQ: Protective effect of SGK1 in rat hippocampal neurons subjected to ischemia reperfusion. Cell Physiol Biochem 2014;34:299-312.

23 Lang PA, Graf D, Boini KM, Lang KS, Klingel K, Kandolf R, Lang F: Cell volume, the serum and glucocorticoid inducible kinase 1 and the liver. Z Gastroenterol 2011;49:713-719.

24 Wulff P, Vallon V, Huang DY, Völkl H, Yu F, Richter K, Jansen M, Schlunz M, Klingel K, Loffing J, Kauselmann G, Bosl MR, Lang F, Kuhl D: Impaired renal $\mathrm{Na}(+)$ retention in the sgk1-knockout mouse. J Clin Invest 2002;110:1263-1268.

25 Chraïbi A, Renauld S: PPAR $\gamma$-induced stimulation of amiloride-sensitive sodium current in renal collecting duct principal cells is serum and insulin dependent. Cell Physiol Biochem 2014;33:581-593.

26 Wu C, Yosef N, Thalhamer T, Zhu C, Xiao S, Kishi Y, Regev A, Kuchroo VK: Induction of pathogenic TH17 cells by inducible salt-sensing kinase SGK1. Nature 2013;496:513-517.

27 Sobiesiak M, Shumilina E, Lam RS, Wölbing F, Matzner N, Kaesler S, Zemtsova IM, Lupescu A, Zahir N, Kuhl D, Schaller M, Biedermann T, Lang F: Impaired mast cell activation in gene-targeted mice lacking the serum- and glucocorticoid-inducible kinase SGK1. J Immunol 2009;183:4395-4402.

28 Lang F, Böhmer C, Palmada M, Seebohm G, Strutz-Seebohm N, Vallon V: (Patho)physiological significance of the serum- and glucocorticoid-inducible kinase isoforms. Physiol Rev 2006;86:1151-1178.

29 García-Martínez JM, Alessi DR: mTOR complex 2 (mTORC2) controls hydrophobic motif phosphorylation and activation of serum- and glucocorticoid-induced protein kinase 1 (SGK1). Biochem J 2008;416:375385.

30 Hong F, Larrea MD, Doughty C, Kwiatkowski DJ, Squillace R, Slingerland JM: mTOR-raptor binds and activates SGK1 to regulate p27 phosphorylation. Mol Cell 2008;30:701-711.

31 Sommer EM, Dry H, Cross D, Guichard S, Davies BR, Alessi DR: Elevated SGK1 predicts resistance of breast cancer cells to Akt inhibitors. Biochem J 2013;452:499-508.

32 Hall BA, Kim TY, Skor MN, Conzen SD: Serum and glucocorticoid-regulated kinase 1 (SGK1) activation in breast cancer: requirement for mTORC1 activity associates with ER-alpha expression. Breast Cancer Res Treat 2012;135:469-479.

33 Zheng G, Jia X, Peng C, Deng Y, Yin J, Zhang Z, Li N, Deng M, Liu X, Liu H, Lu M, Wang C, Gu Y, He Z: The miR-491-3p/mTORC2/FOX01 regulatory loop modulates chemo-sensitivity in human tongue cancer. Oncotarget 2015;6:6931-6943.

34 Stringer-Reasor EM, Baker GM, Skor MN, Kocherginsky M, Lengyel E, Fleming GF, Conzen SD: Glucocorticoid receptor activation inhibits chemotherapy-induced cell death in high-grade serous ovarian carcinoma. Gynecol Oncol 2015;138:656-662.

35 Isikbay M, Otto K, Kregel S, Kach J, Cai Y, Vander Griend DJ, Conzen SD, Szmulewitz RZ: Glucocorticoid receptor activity contributes to resistance to androgen-targeted therapy in prostate cancer. Horm Cancer 2014;5:72-89.

36 Fagerli U-M, Ullrich K, Stühmer T, Holien T, Köchert K, Holt RU, Bruland O, Chatterjee M, Nogai H, Lenz G, Shaughnessy JD Jr, Mathas S, Sundan A, Bargou RC, Dörken B, Børset M, Janz M: Serum/glucocorticoidregulated kinase 1 (SGK1) is a prominent target gene of the transcriptional response to cytokines in multiple myeloma and supports the growth of myeloma cells. Oncogene 2011;30:3198-3206. 


\section{Cellular Physiology Cell Physiol Biochem 2016;39:1863-1876 \begin{tabular}{l|l|l|}
\hline DOI: 10.1159/000447885 & $\begin{array}{l}\text { C) 2016 The Author(s). Published by S. Karger AG, Basel } \\
\text { www.karger.com/cpb }\end{array}$
\end{tabular} \\ Talarico et al.: SGK1 in Chemo- and Radio-Resistance}

37 Abbruzzese C, Mattarocci S, Pizzuti L, Mileo AM, Visca P, Antoniani B, Alessandrini G, Facciolo F, Amato R, D'Antona L, Rinaldi M, Felsani A, Perrotti N, Paggi MG: Determination of SGK1 mRNA in non-small cell lung cancer samples underlines high expression in squamous cell carcinomas. J Exp Clin Cancer Res 2012;31:4.

38 Xiaobo Y, Qiang L, Xiong Q, Zheng R, Jianhua Z, Zhifeng L, Yijiang S, Zheng J: Serum and glucocorticoid kinase 1 promoted the growth and migration of non-small cell lung cancer cells. Gene 2016;576:339-346.

39 Huang AH, Pan SH, Chang WH, Hong QS, Chen JJW, Yu SL: PARVA Promotes Metastasis by Modulating ILK Signalling Pathway in Lung Adenocarcinoma. PLoS One 2015;10:e0118530.

40 Davidson B, Abeler VM, Førsund M, Holth A, Yang Y, Kobayashi Y, Chen L, Kristensen GB, Shih IeM, Wang TL: Gene expression signatures of primary and metastatic uterine leiomyosarcoma. Hum Pathol 2014;45:691-700.

41 Tangir J, Bonafé N, Gilmore-Hebert M, Henegariu 0, Chambers SK: SGK1, a potential regulator of c-fms related breast cancer aggressiveness. Clin Exp Metastasis 2004;21:477-483.

42 Qin J, Chen JX, Zhu Z, Teng JA: Genistein inhibits human colorectal cancer growth and suppresses miR-95, Akt and SGK1. Cell Physiol Biochem 2015;35:2069-2077.

43 Nasir O, Wang K, Föller M, Gu S, Bhandaru M, Ackermann TF, Boini KM, Mack A, Klingel K, Amato R, Perrotti N, Kuhl D, Behrens J, Stournaras C, Lang F: Relative resistance of SGK1 knockout mice against chemical carcinogenesis. IUBMB Life 2009;61:768-776.

44 Amato R, D’Antona L, Porciatti G, Agosti V, Menniti M, Rinaldo C, Costa N, Bellacchio E, Mattarocci S, Fuiano G, Soddu S, Paggi MG, Lang F, Perrotti N: Sgk1 activates MDM2-dependent p53 degradation and affects cell proliferation, survival, and differentiation. J Mol Med (Berl) 2009;87:1221-1239.

45 Amato R, Scumaci D, D’Antona L, Iuliano R, Menniti M, Di Sanzo M, Faniello MC, Colao E, Malatesta P, Zingone A, Agosti V, Costanzo FS, Mileo AM, Paggi MG, Lang F, Cuda G, Lavia P, Perrotti N: Sgk1 enhances RANBP1 transcript levels and decreases taxol sensitivity in RKO colon carcinoma cells. Oncogene 2013;32:4572-4578.

46 Gdowski A, Panchoo M, Treuren T Van, Basu A: Emerging therapeutics for targeting Akt in cancer. Front Biosci 2016;21:757-768.

47 Li X, Wu C, Chen N, Gu H, Yen A, Cao L, Wang E, Wang L: PI3K/Akt/mTOR signaling pathway and targeted therapy for glioblastoma. Oncotarget DOI: 10.18632/oncotarget.7961.

48 Murray JT, Campbell DG, Morrice N, Auld GC, Shpiro N, Marquez R, Peggie M, Bain J, Bloomberg GB, Grahammer F, Lang F, Wulff P, Kuhl D, Cohen P: Exploitation of KESTREL to identify NDRG family members as physiological substrates for SGK1 and GSK3. Biochem J 2004;384:477-488.

49 Melotte V, Qu X, Ongenaert M, van Criekinge W, de Bruïne AP, Baldwin HS, van Engeland M: The $\mathrm{N}$-myc downstream regulated gene (NDRG) family: diverse functions, multiple applications. FASEB J 2010;24:4153-4166.

50 Weiler M, Blaes J, Pusch S, Sahm F, Czabanka M, Luger S, Bunse L, Solecki G, Eichwald V, Jugold M, Hodecker S, Osswald M, Meisner C, Hielscher T, Rübmann P, Pfenning PN, Ronellenfitsch M, Kempf T, Schnölzer M, Abdollahi A, Lang F, Bendszus M, von Deimling A, Winkler F, Weller M, Vajkoczy P, Platten M, Wick W: mTOR target NDRG1 confers MGMT-dependent resistance to alkylating chemotherapy. Proc Natl Acad Sci USA 2014;111:409-414.

51 Kokame K, Kato H, Miyata T: Homocysteine-respondent genes in vascular endothelial cells identified by differential display analysis. GRP78/BiP and novel genes. J Biol Chem 1996;271:29659-29665.

52 Zhou D, Salnikow K, Costa M: Cap43, a novel gene specifically induced by Ni2+ compounds. Cancer Res 1998;58:2182-2189.

53 Kurdistani SK, Arizti P, Reimer CL, Sugrue MM, Aaronson SA, Lee SW: Inhibition of tumor cell growth by RTP/rit42 and its responsiveness to p53 and DNA damage. Cancer Res 1998;58:4439-4444.

54 Park H, Adams MA, Lachat P, Bosman F, Pang SC, Graham CH: Hypoxia induces the expression of a 43-kDa protein (PROXY-1) in normal and malignant cells. Biochem Biophys Res Commun 2000;276:321-328.

55 Lang F, Artunc F, Vallon V: The physiological impact of the serum and glucocorticoid-inducible kinase SGK1. Curr Opin Nephrol Hypertens 2009;18:439-448.

56 Weiler M, Blaes J, Pusch S, Sahm F, Czabanka M, Luger S, Bunse L, Solecki G, Eichwald V, Jugold M, Hodecker S, Osswald M, Meisner C, Hielscher T, Rübmann P, Pfenning PN, Ronellenfitsch M, Kempf T, Schnölzer M, Abdollahi A, Lang F, Bendszus M, von Deimling A, Winkler F, Weller M, Vajkoczy P, Platten M, Wick W.: mTOR target NDRG1 confers MGMT-dependent resistance to alkylating chemotherapy. Proc Natl Acad Sci USA 2014;111:409-414. 


\section{Cellular Physiology Cell Physiol Biochem 2016;39:1863-1876 \begin{tabular}{l|l|l|}
\hline and Biochemistry 10.1159/000447885 & $\begin{array}{l}\text { C) } 2016 \text { The Author(s). Published by S. Karger AG, Basel } \\
\text { www.karger.com/cpb }\end{array}$ \\
\hline
\end{tabular} \\ Talarico et al.: SGK1 in Chemo- and Radio-Resistance}

57 Kim MJ, Chae JS, Kim KJ, Hwang SG, Yoon KW, Kim EK, Yun HJ, Cho JH, Kim J, Kim BW, Kim HC, Kang SS, Lang F, Cho SG, Choi EJ: Negative regulation of SEK1 signaling by serum- and glucocorticoid-inducible protein kinase 1. EMBO J 2007;26:3075-3085.

58 Skor MN, Wonder EL, Kocherginsky M, Goyal A, Hall BA, Cai Y, Cai Y, Conzen SD: Glucocorticoid receptor antagonism as a novel therapy for triple-negative breast cancer. Clin Cancer Res 2013;19:6163-6172.

59 Park H-S, Kim M-S, Huh S-H, Park J, Chung J, Kang SS, Choi EJ: Akt (protein kinase B) negatively regulates SEK1 by means of protein phosphorylation. J Biol Chem 2002;277:2573-2578.

60 Sahoo S, Brickley DR, Kocherginsky M, Conzen SD: Coordinate expression of the PI3-kinase downstream effectors serum and glucocorticoid-induced kinase (SGK-1) and Akt-1 in human breast cancer. Eur J Cancer 2005;41:2754-2759.

61 Zhang L, Cui R, Cheng X, Du J: Antiapoptotic effect of serum and glucocorticoid-inducible protein kinase is mediated by novel mechanism activating I\{kappa\}B kinase.Cancer Res 2005;65:457-464.

62 Ciciarello M, Mangiacasale R, Lavia P: Spatial control of mitosis by the GTPase Ran. Cell Mol Life Sci 2007;64:1891-1914.

63 Kalab P, Heald R: The RanGTP gradient - a GPS for the mitotic spindle. J Cell Sci 2008;121:1577-1586.

64 Clarke PR, Zhang C: Spatial and temporal coordination of mitosis by Ran GTPase. Nat Rev Mol Cell Biol 2008;9:464-477.

65 Xu X, Jia R, Zhou Y, Song X, Wang J, Qian G, Ge S, Fan X: Microarray-based analysis: identification of hypoxiaregulated microRNAs in retinoblastoma cells. Int J Oncol 2011;38:1385-1393.

66 Li X, Liu Y, Granberg KJ, Wang Q, Moore LM, Ji P, Gumin J, Sulman EP, Calin GA, Haapasalo H, Nykter M, Shmulevich I, Fuller GN, Lang FF, Zhang W: Two mature products of MIR-491 coordinate to suppress key cancer hallmarks in glioblastoma. Oncogene 2015;34:1619-1628.

67 Zheng G, Jia X, Peng C, Deng Y, Yin J, Zhang Z, Li N, Deng M, Liu X, Liu H, Lu M, Wang C, Gu Y, He Z: The miR-491-3p/mTORC2/FOX01 regulatory loop modulates chemo-sensitivity in human tongue cancer. Oncotarget 2015;6:6931-6943.

68 Feng Z, Liu L, Zhang C, Zheng T, Wang J, Lin M, Zhao Y, Wang X, Levine AJ, Hu W: Chronic restraint stress attenuates p53 function and promotes tumorigenesis. Proc Natl Acad Sci USA 2012;109:7013-7018.

69 Towhid ST, Liu G-L, Ackermann TF, Beier N, Scholz W, Fuchß T, Toulany M, Rodemann HP, Lang F: Inhibition of colonic tumor growth by the selective SGK inhibitor EMD638683. Cell Physiol Biochem 2013;32:838848.

70 Liu G, Honisch S, Liu G, Schmidt S, Pantelakos S, Alkahtani S, Toulany M, Lang F, Stournaras C: Inhibition of SGK1 enhances mAR-induced apoptosis in MCF-7 breast cancer cells. Cancer Biol Ther 2015;16:52-59.

71 Talarico C, D’Antona L, Scumaci D, Barone A, Gigliotti F, Fiumara CV, Dattilo V, Gallo E, Visca P, Ortuso F, Abbruzzese C, Botta L, Schenone S, Cuda G, Alcaro S, Bianco C, Lavia P, Paggi MG, Perrotti N, Amato R: Preclinical model in HCC: the SGK1 kinase inhibitor SI113 blocks tumor progression in vitro and in vivo and synergizes with radiotherapy. Oncotarget 2015;6:37511-37525.

72 Talarico C, Dattilo V, D’Antona L, Barone A, Amodio N, Belviso S, Musumeci F, Abbruzzese C, Bianco C, Trapasso F, Schenone S, Alcaro S, Ortuso F, Florio T, Paggi MG, Perrotti N, Amato R: SI113, a SGK1 inhibitor, potentiates the effects of radiotherapy, modulates the response to oxidative stress and induces cytotoxic autophagy in human glioblastoma multiforme cells. Oncotarget 2016;7:15868-15884.

73 Sherk AB, Frigo DE, Schnackenberg CG, Bray JD, Laping NJ, Trizna W, Hammond M, Patterson JR, Thompson SK, Kazmin D, Norris JD, McDonnell DP.: Development of a small-molecule serum- and glucocorticoid-regulated kinase-1 antagonist and its evaluation as a prostate cancer therapeutic. Cancer Res 2008;68:7475-7483.

74 Berdel HO, Yin H, Liu JY, Grochowska K, Middleton C, Yanasak N, Abdelsayed R, Berdel WE, Mozaffari M, Yu JC, Baban B: Targeting serum glucocorticoid-regulated kinase-1 in squamous cell carcinoma of the head and neck: a novel modality of local control. PLoS One 2014;9:e113795.

75 Mansley MK, Wilson SM: Effects of nominally selective inhibitors of the kinases PI3K, SGK1 and PKB on the insulin-dependent control of epithelial Na+ absorption. Br J Pharmacol 2010;161:571-588.

76 Ackermann TF, Boini KM, Beier N, Scholz W, Fuchss T, Lang F: EMD638683, a novel SGK inhibitor with antihypertensive potency. Cell Physiol Biochem 2011;28:137-146. 


\section{Cellular Physiology Cell Physiol Biochem 2016;39:1863-1876

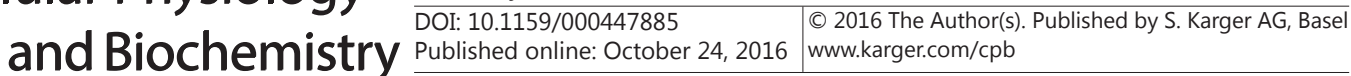 \\ Talarico et al.: SGK1 in Chemo- and Radio-Resistance}

77 Ortuso F, Amato R, Artese A, D'antona L, Costa G, Talarico C, Gigliotti F, Bianco C, Trapasso F, Schenone S, Musumeci F, Botta L, Perrotti N, Alcaro S: In silico identification and biological evaluation of novel selective serum/glucocorticoid-inducible kinase 1 inhibitors based on the pyrazolo-pyrimidine scaffold. J Chem Inf Model 2014;54:1828-1832.

78 D’Antona L, Amato R, Talarico C, Ortuso F, Menniti M, Dattilo V, Iuliano R, Gigliotti F, Artese A, Costa G, Schenone S, Musumeci F, Abbruzzese C, Botta L,Trapasso F, Alcaro S, Paggi MG, Perrotti N: SI113, a Specific Inhibitor of the Sgk1 Kinase Activity that Counteracts Cancer Cell Proliferation. Cell Physiol Biochem 2015;35:2006-2018.

79 Chung EJ, Sung YK, Farooq M, Kim Y, Im S, Tak WY, Hwang YJ, Kim YI, Han HS, Kim JC, Kim MK: Gene expression profile analysis in human hepatocellular carcinoma by cDNA microarray. Mol Cells 2002;14:382-387.

80 Won M, Park KA, Byun HS, Kim YR, Choi BL, Hong JH, Park J, Seok JH, Lee YH, Cho CH, Song IS, Kim YK, Shen HM, Hur GM: Protein kinase SGK1 enhances MEK/ERK complex formation through the phosphorylation of ERK2: Implication for the positive regulatory role of SGK1 on the ERK function during liver regeneration. J Hepatol 2009;51:67-76.

81 Wang X, Bhattacharyya D, Dennewitz MB, Kalinichenko V V, Zhou Y, Lepe R, Costa RH: Rapid hepatocyte nuclear translocation of the Forkhead Box M1B (FoxM1B) transcription factor caused a transient increase in size of regenerating transgenic hepatocytes. Gene Expr 2003;11:149-162.

82 Zhang MS, Arnaoutov A, Dasso M: RanBP1 Governs Spindle Assembly by Defining Mitotic Ran-GTP Production. Dev Cell 2014;31:393-404.

83 Di Fiore B, Ciciarello M, Mangiacasale R, Palena A, Tassin A-M, Cundari E, Lavia P: Mammalian RanBP1 regulates centrosome cohesion during mitosis. J Cell Sci 2003;116:3399-3411.

84 Rensen WM, Roscioli E, Tedeschi A, Mangiacasale R, Ciciarello M, Di Gioia SA, Lavia P: RanBP1 downregulation sensitizes cancer cells to taxol in a caspase-3-dependent manner. Oncogene 2009;28:1748-1758.

85 Tedeschi A, Ciciarello M, Mangiacasale R, Roscioli E, Rensen WM, Lavia P: RANBP1 localizes a subset of mitotic regulatory factors on spindle microtubules and regulates chromosome segregation in human cells. J Cell Sci 2007;120:3748-3761.

86 Li HY, Ng WP, Wong CH, Iglesias PA, Zheng Y: Coordination of chromosome alignment and mitotic progression by the chromosome-based Ran signal. Cell Cycle 2007;6:1886-1895.

87 Perry ME: Mdm2 in the response to radiation. Mol Cancer Res 2004;2:9-19.

88 Yan X, Chua M-S, Sun H, So S: N-Myc down-regulated gene 1 mediates proliferation, invasion, and apoptosis of hepatocellular carcinoma cells. Cancer Lett 2008;262:133-142.

89 Delprato A: Topological and functional properties of the small GTPases protein interaction network. PLoS One 2012;7:e44882.

90 Wong CM, Wei L, Au SL, Fan DN, Zhou Y, Tsang FH, Law CT, Lee JM, He X, Shi J, Wong CC, Ng IO: MiR200b/200c/429 subfamily negatively regulates Rho/ROCK signaling pathway to suppress hepatocellular carcinoma metastasis. Oncotarget 2015;6:13658-13670.

91 Chen H, Miao J, Li H, Wang C, Li J, Zhu Y, Wang J, Wu X, Qiao H: Expression and prognostic significance of p21-activated kinase 6 in hepatocellular carcinoma. J Surg Res 2014;189:81-88.

$92 \mathrm{Xu} \mathrm{Z}$, Wu J, Zha X: Up-regulation of prohibitin 1 is involved in the proliferation and migration of liver cancer cells. Sci China Life Sci 2011;54:121-127. 